\title{
Mitochondrial Encephalo-Myopathy, Lactic Acidosis and Stroke Like Syndrome (MELAS): A Case Report
}

\author{
KAZI ASHRAFUL ISLAM ${ }^{1}$, MD. MIZANUR RAHMAN ${ }^{2}$, SHAHEEN AKHTER ${ }^{3}$, SYEDATABASSUM ALAM ${ }^{4}$, \\ MAHBUB MUTANABBI ${ }^{5}$
}

\section{Introduction}

Mitochondrial Encephalomyopathy, Lactic Acidosis and Stroke like syndrome (MELAS) is a rare neurodegenerative inherited disorder ${ }^{1}$. The epidemiology of mitochondrial disorders found a prevalence of more than 10.2 per 100,000 live birth but no data concerning the prevalence of MELAS ${ }^{2}$. MELAS is a very rare genetic disorder, transmitted by maternal mode of inheritance. Though mode of inheritance is mitochondrial but new mutation may occur $^{3}$. All MELAS cases are associated with ragged red fibres in skeletal muscle and elevated blood lactate. The main pathology is structural and functional abnormalities of mitochondrial DNA. The basic defect is in the $A$ to $G$ substitution of $t$ RNA at bp 3243 of the mitochondrial DNA, which affect mainly aerobic cellular metabolism at the level of electron transport chain ${ }^{4}$. In MELAS multi system organ involvement is found including the central nervous system (CNS), skeletal muscle, eye, cardiac muscle, gastrointestinal system and renal system. Predominance of central nervous system involvement suggest CNS mitochondria are affected more ${ }^{5}$. MELAS usually present in childhood with short stature, seizure disorder, stroke like event, diabetes mellitus, hearing loss and lactic acidosis ${ }^{6}$. As it is a progressive degenerative disorder most cases usually die within $2^{\text {nd }}$ decade ${ }^{7}$. Because of rarity of this syndrome, we like to report the case.

\section{Case Report}

A 14 years old boy was admitted at Bangabandhu Sheikh Mujib Medical University (BSMMU) in March 2008 with the complains of fever, headache, vomiting, convulsion and left sided weakness of the body for

1. Consultant, Department of Paediatrics, Bangabandhu Sheikh Mujib Medical University, Dhaka

2. Professor, Paediatric Neurology, Department of Paediatrics, Bangabandhu Sheikh Mujib Medical University, Dhaka

3. Associate Professor, Paediatric Neurology, Department of Paediatrics, Bangabandhu Sheikh Mujib Medical University, Dhaka

4. Assistant Professor, Paediatric Neurology, Department of Paediatrics, Bangabandhu Sheikh Mujib Medical University, Dhaka

5. Assistant Professor, Department of Paediatrics, Bangabandhu Sheikh Mujib Medical University, Dhaka

Correspondence: Dr. Kazi Ashraful Islam two days. Seizures was generalized tonic-clonic in nature that lasted for ten minutes. He had a history of repeated episodes of weakness of one side of his body associated with seizures for the last four years. Each episode his complains were gradually resolved within few weeks with some impairment. Parents noticed the boy was reasonably well up to 4 years of age since then he was not growing well with his peers, was less interested to engage any physical activity and became easily fatigue. His developmental mile stone was age appropriate up to 4 years of age, since then motor and language delay were evident. He complained of poor vision and hearing impairment. His school performance was below average.

The boy had a normal antenatal and perinatal history. There is no history of consanguinity of marriage in his family. He is the fourth issue of his parents. All of his family members including maternal uncle or cousin are in good health.

On examination, the boy was apathy, least interested to surroundings, grossly emaciated, stunted, and general physical examination findings including vital signs were within normal limit. His weight was $14 \mathrm{~kg}$ and weight for age $Z$ score was - 5 SD. His height was $115 \mathrm{~cm}$ and height for age $Z$ score was -6SD, and had small head circumference $(50 \mathrm{~cm})$, at $3^{\text {rd }}$ percentile for age.

Neurological examination revealed slurred speech, poor vision and hearing impairment. Intellectually he performed at a 7 years old level and could recall only one of the three objects at five minutes. Cranial nerves except 2nd and 3rd were intact. Muscle bulk, tone and strength were symmetrically reduced. Deep tendon reflexes (DRT) were decreased, bilateral planter reflexes were flexor, sensory function was intact. On funduscopic examination, signs of optic atrophy were found in both eyes. Audiometry revealed bilateral moderate mixed type of hearing loss.

Laboratory evaluation revealed positive findings include, very high blood lactate $58.84 \mathrm{mg} / \mathrm{dl}$ (normal range 3-7 $\mathrm{mg} / \mathrm{dl}$ ), very high SGPT $1091 \mathrm{U} / \mathrm{L}$ (normal range up to $40 \mathrm{U} / \mathrm{L}$ ). Ultrasonogram of abdomen showed 


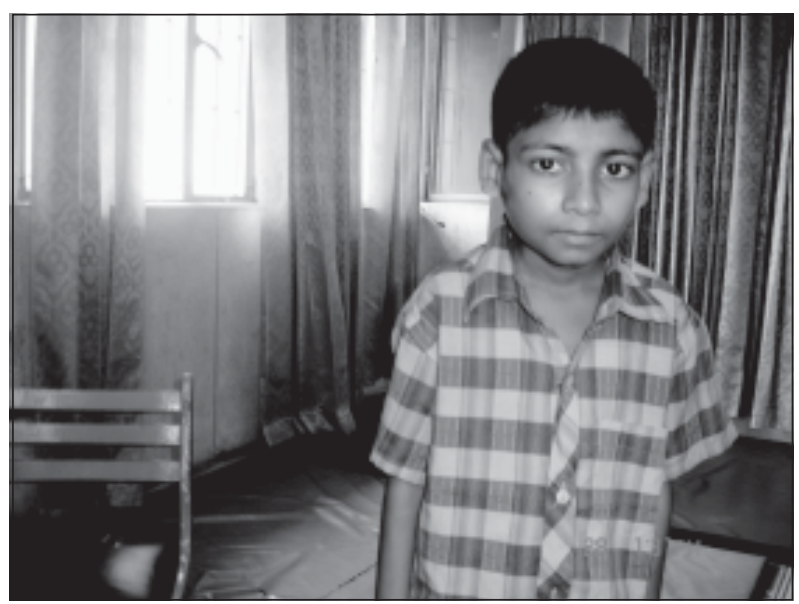

Fig.-1: Photograph of the patient

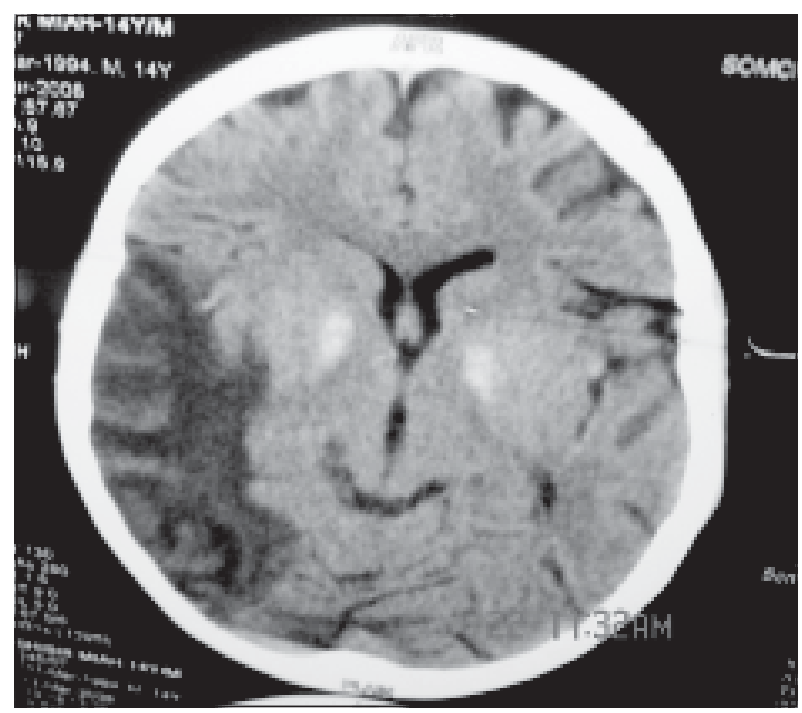

Fig.-2: CT scan of brain shows infarction in right temporo-parieto-occipital region and bilateral basal ganglia calcification.

cholelithiasis and pancreatic calculi. An electroencephalogram (EEG) showed focal epileptiform discharge. Computed tomography (CT scan) of brain showed hypointense signal in right temporopraietal region suggestive of infarction involving area of middle cerebral artery and also bilateral basal ganglia calcification. Other relevant investigation including complete blood count, stool and urine routine examination, renal function test, serum electrolytes, creatininephosphokinase (CPK), growth hormone $(\mathrm{GH})$, blood ammonium, electrocardiography (ECG), echocardiogram and chest skiagram revealed no abnormalities. Muscle biopsy to detect ragged red fibers and genetic studies to pinpoint the exact nature of the defect in our case could not be done due to lack of facility. As there is no specific treatment available for MELASs conservative management was advised like avoidance of unnecessary activities and some drugs like valproic acid. Carnitine and coenzyme $\mathrm{Q}_{10}$ were given as a supplement. Phenytoin was given for control of seizure.

\section{Discussion}

Symptoms of MELAS begins between age 3 and 11 years ${ }^{1}$. In our case symptoms started at 4 years of age. MELAS cases usually present with stroke like event, weakness, easy fatigability, exercise intolerance, developmental delay, learning disability, attention deficit disorder, failure to thrive, focal or generalized seizures, visual abnormalities, hemiplegia, migraine or migraine like headaches ${ }^{4}$. All of the above features were found in this case. Ophthalmoplegia, blindness due to optic atrophy, pigmentary retinopathy are occasional findings ${ }^{2}$. This patient had only optic atrophy with low vision. Sensory neural hearing loss was found in some cases $^{5}$. This patient had moderate mixed hearing loss. Diabetes mellitus, palpitations, shortness of breath were found in some cases ${ }^{8}$. This boy had no such findings. Some MELAS cases had gastrointestinal symptoms like abdominal pain and vomiting ${ }^{9,10}$. He had vomiting and abdominal pain on several occasions and on USG of abdomen showed cholelithiasis and pancreatic calculi. Peripheral neuropathy, renal problems and dental problems were noticed in some patients ${ }^{11}$. This patient had no such features. Elevated blood lactate is an important component of MELAS ${ }^{4}$. $\mathrm{He}$ had very high blood lactate level of $58.4 \mathrm{mg} / \mathrm{dl}$. Cardiomyopathy or conduction defect may be present in some cases ${ }^{12}$. His ECG and Echocardiogram revealed no abnormalities. In MELAS usual EEG findings are focal or generalized epileptiform discharge ${ }^{11}$. Patient's EEG showed focal epileptiform discharge. Neuroimaging abnormality following a stroke like episode revealed regional lucency, cerebral atrophy or calcification ${ }^{2}$. CT scan of brain of our patient showed lucencies in right temporo-parietal area and bilateral basal ganglia calcification.

\section{Conclusion}

As short stature is a constant feature of MELAS, so if a child presented with short stature and stroke like event, i.e., headache, vomiting, seizure and hemiparesis should be evaluated for metabolic disorder like MELAS. As it is a progressive disease and has no curative treatment, early identification and supportive measure may give some benefit. 


\section{References}

1. Hirano M, Ricci E, Rowland LP. Clinical definition of MELAS [Abstract]. Ann Neurol 1991; 30: 299.

2. Fernando S. MELAS Syndrome. e Medicine Pedictrics. Updated (http://www.e medicine. medscape.com/article/ 946844 over view, accessed on 23 July, 2009).

3. Mehrazin M, Shanske S, Kaufmann P, Wei Y, Coku J. Longitudinal changes of mt DNAA3243G mutation load and level of functioning in MELAS. Am J Med Genet 2009; 149: 584-87.

4. Ciafaloni E, Ricci ER, Stanske S, Moraes CT, Silvestri G, Hiramo M, et al. MELAS clinical features, biochemistry, and molecular genetics. Ann Neurol 1992; 31: 391-98.

5. Hirano M, Pavlakis SG. Mitochondrial myopathy, encephalopathy, lactic acidosis and strokelike episodes (MELAS) current concept. J Child Neurol 1994; 9: 4-13.

6. Pavlakis SG, Philips PC, DiMauro S, De Vivo DC, Roland LP. Mitochondrial myopathy, encephalopathy, lactic acidosis and stroke like episodes: a distinctive clinical syndrome. Ann Neurol 1984; 16: 481-88.
7. B Shing, PS Low, JF Yeo. MELAS: A Case Report. Annals Academy of Medicine 2004; 33 (Suppl): S69-71.

8. Joko $T$, Iwashige $K$, Hashimoto $T$. A case of mitochondrial encephalomyopathy, lactic acidosis and stroke like episodes associated with diabetes mellitus and hypothalamo-pituitary dysfunction. Endocr J 1997; 44: 805-09.

9. Shimotake T, Furukawa T, Inoue K, Iwai N, Takeuchi Y. Familial occurrence of intestinal obstruction in children with syndrome of mitochondrial enccphalomyopathy, lactic acidosis, and stroke like episodes (MELAS). J Pedeatr Surg 1998; 33: 1837-39.

10. Kishi T, Kawahara H, Tanaka T, Kaneco Y, Tsuji $\mathrm{T}$, Hiroshi K, et al. Superior mesenteric artery syndrome complicating mitochondrial encephalopathy. J Peditric Gastroenterol Neutr 1998; 26: 464-67.

11. Matsumoto J, Saver JL, Brennan KC, Ringman JM. Mitochondrial encephalomyopathy with lactic acidosis and stroke (MELAS). Rev Neurol Dis 2005; 2: 30-34.

12. Hirano M, Ricci E, Koenigsberger MR. MELAS: an original case and clinical criteria for diagnosis. Neuromuscular Disord 1992; 2: 125-45. 